\title{
Family-centered empowerment process in individuals with spinal cord injury living in Iran: a grounded theory study
}

\author{
Maryam Shabany $\mathbb{1 D}^{1} \cdot$ Alireza NikbakhtNasrabadi ${ }^{1,2} \cdot{\text { Nooredin } \text { Mohammadi }^{3} \cdot \text { Sheri D. Pruitt }}^{4}$
}

Received: 31 March 2019 / Revised: 9 August 2019 / Accepted: 15 August 2019 / Published online: 2 September 2019

(c) The Author(s), under exclusive licence to International Spinal Cord Society 2019

\begin{abstract}
Study design This was a qualitative study using grounded theory method.

Objectives To explain the process of family-centered empowerment in a population of individuals with SCI living in Iran. Setting Brain and SCI Research Center, Social Welfare Center, and SCI Association of Tehran; Iran.

Methods Participants were 19 persons with traumatic SCI, 13 family member caregivers, and 11 health care providers selected through purposeful sampling. Data were collected using face-to-face, semi-structured interviews, which were continued until data saturation. The interview data were methodically collected and analyzed using Strauss and Corbin's (1998) recommended method for grounded theory. Constant comparative analysis was simultaneously conducted through reviews of the interview statements, observations of behavior, interviewer field notes, and interviewer memos. The analysis was managed in MAXQDA software version 10.

Results The process of family-centered empowerment following SCI included five categories: (1) disruption in the existential integrity of the individual; (2) constructive life recovery; (3) inhibitors of family-centered empowerment; (4) facilitators of family-centered empowerment, and (5) back on track. Constructive life recovery was selected as the core variable using the grounded theory method. This core variable identified the strategies most frequently used by the participants to cope with the challenges of SCI-related impairment, disability, and overall life management.

Conclusions Family-centered empowerment process in individuals with SCI living in Iran emerged from the data. The model includes early disruptions in the bio-psycho-social and vocational lives of individuals with SCI and their families, strategies for recovery post injury, inhibitors and facilitators of family-centered empowerment, the gradual return to work and daily activities, and the expected social roles for individuals with SCI.
\end{abstract}

Supplementary information The online version of this article (https:// doi.org/10.1038/s41393-019-0348-3) contains supplementary material, which is available to authorized users.

Alireza NikbakhtNasrabadi

nikbakht@tums.ac.ir

1 Brain and Spinal Cord Injury Research Center, Neuroscience Institute, Tehran University of Medical Sciences, Tehran, Iran

2 Dept. of Medical Surgical Nursing \& Dean for International Affairs, Nursing and Midwifery School, Tehran University of Medical Sciences, Tehran, Iran

3 Dept. of Critical Care Nursing, Nursing and Midwifery School, Iran University of Medical Sciences, Tehran, Iran

4 Former Director, Behavioral Science Integration Kaiser Permanente, The Permanente Medical Group, North Valley, Sacramento, CA, USA

\section{Introduction}

Spinal cord injury (SCI) is among the most devastating problems of the central nervous system [1], afflicting patients not only with sensory-motor problems, but often with numerous physical complications for the remainder of their lives. Autonomic dysreflexia, urinary tract stones, urinary infections, anal sphincter dysfunction, decubiti ulcers, heterotopic ossification, osteoporosis, stiff joints, and sexual problems are some of the complications that may add to the impairment $[2,3]$.

The World Health Organization reported that worldwide, $250,000-500,000$ people suffer from SCI, which is associated with considerable costs for individuals and societies [4]. In Iran, the prevalence of traumatic spinal injury in Tehran was reported as 1.2-11.4 injuries for every 10,000 people from 2008 to 2009 [5]. 
Costs of care for SCI and its secondary conditions may impose a heavy financial burden on all involved [6, 7]. Persons with SCI often face multiple challenges that extend beyond physical impairment and disability, including the absence of financial, emotional, psychological, and social support. Moreover, their families often are the primary source of care [8].

Families are the most valuable, yet most vulnerable, source of care, and support for their family member with chronic healthcare needs [9]. If they accept the responsibility of providing care, they often are exposed to numerous psychological and social issues, themselves [10]. In fact, the management of a chronic condition at home can be a very complex and time consuming activity that far surpass mere medical treatment [11]. Many of the social and psychological complexities associated with having SCI are often ignored by professional healthcare providers making family support even more challenging. Yet, management for these devastating injuries are next to impossible without the involvement of families [11]. Strategies for helping both individuals and families play an active healthcare role must emphasize empowerment that extends beyond the provision of traditional medical services [12].

In this way financial, social, and emotional dimensions of the lives of patients, their families, and societies can better be addressed. For example, caregivers can assist patients in enhancing their quality of life and can play a role in decreasing social and psychological impairment that often comes with chronic illness [13]. Moreover, to be most effective, healthcare providers need to leverage family caregivers and engage both patients and families in the process of empowerment to promote everyone's long term health and well-being [9].

Family-centered care for persons with SCI may be more challenging than care for other chronic health problems. The management of SCI is a multidimensional (physical, psychological, social, cognitive, cultural, and economic) process, which is influenced by various underlying factors [14]. Understanding this process-which starts from the moment of hospital admission and goes through discharge to home and return to society-depends on socio-cultural factors, multidisciplinary interactions in dynamic contexts that occur between healthcare providers, individuals with SCI and their family caregivers.

Grounded theory method (GTM) is a systematic research methodology used in the social sciences that involves the construction of theory through methodical gathering and analysis of data [15]. GTM works inductively, often beginning with a question or with the collection of qualitative data to study social interactions, structures, and processes. GTM was employed in the current study to examine persons with SCI, their families, and their healthcare providers in their respective lives and roles. Thus, for the first time in Iran, we aim to explain the process of familycentered empowerment for individuals with SCI using GTM.

\section{Methods and participants}

\section{Study design}

This study was a qualitative study using GTM, to investigate the process of family-centered empowerment in individuals with SCI in Iran [16].

\section{Methodology}

Family-centered empowerment is a complex and multidimensional phenomenon, and there is little information about it available in scientific literature. GTM was useful to gather information to improve our understanding of social processes and human interactions by collecting free expression of emotions, reported behaviors, and the participants' life experiences [17].

\section{Ethical considerations}

This study was approved by Institutional review Board at Tehran University of Medical Sciences (No. IR.TUMS. REC.1394.1493). Participants voluntarily participated in this study and could refuse to participate or withdraw at any time for any reason. Furthermore, participants were informed that all identifying information and responses would be kept confidential. The participants who agreed to join in the study were asked to sign an informed consent document.

\section{Sampling and data collection}

Participants were recruited from three centers in Tehran: Brain and SCI Research Center, Social Welfare Center, and SCI Association of Tehran using a purposeful sampling technique with a maximum variation sampling strategy to ensure maximum variation among those selected to participate [17]. For example, we collected information on gender, marital status, socio-economic level, cultural background, clinical context, and healthcare profession to ensure the sample included a wide breath of participants. Forty-three people agreed to participate: 11 were healthcare providers, 19 were persons with traumatic SCI, and 13 were family caregivers. Recruitment was from November 2015 to October 2017.

The inclusion/exclusion criteria were as follows:

Healthcare providers: willing to participate in the study and share information and experiences; at least 3 years of 
clinical experience with SCI; and Iranian and Farsi/Persian speaking. Persons with SCI: over 18 years of age; traumatic SCI at least 1-year post; diagnosed paraplegia or tetraplegia; without cognitive impairment or head injury; without extremity fractures; not pregnant; and literate.

Family caregivers: any member of a family (sibling, parent, spouse, or child) of a person with SCI for at least 1 year; literate; physically and mentally healthy; responsible for the care of an individual with SCI (caregiver approved by the individual with $\mathrm{SCI}$ ), and not a member of the healthcare treatment team

Data were collected by using semi-structured, face-toface interviews until data saturation (i.e., to the state when data review creates no new codes and the extracted categories are considered coherent and logical) [17]. The interviews were performed at a convenient time and place for the participants, which included participants' homes, private interview rooms in the research center, or in private areas of the hospital. Interviews were 30-90 min in length. Interview questions are presented in Table 1.

\section{Data analysis}

The first author (MS), experienced in qualitative research, employed the analysis strategy recommended by Strauss and Corbin (1998) in which constant comparative analysis is used simultaneously with data collection. In this method, interviews are continuously reviewed, along with observations during the interviews, field notes (written records produced by fieldwork) and memos (records of the researcher's developing ideas about codes and their interconnections). Furthermore, this method has three basic steps: open coding, axial coding, and selective coding [17].

All interviews were transcribed and the responses were reviewed and read several times to get a sense of the general concepts and themes that could be identified and coded (i.e., open coding). Next, these codes were compared with each other and overlapping concepts were combined into specified categories and assigned proper descriptive titles (i.e., axial coding) [17]. Field notes were collected in participants' homes and during occupational therapy sessions in which were the families of individuals with SCI or healthcare providers in order to understand the actions, interactions, verbal, and nonverbal behaviors. These notes were also entered into the software for analysis. The number of initial codes was 2300 . Eventually, these codes were organized into five main categories and seventeen axial categories. This analysis was managed in MAXQDA software version 10 .

\section{Rigor}

The researchers worked to establish trusting relationships and credibility with the participants with the goal of data enrichment and optimal understanding of the experiences being described. Most participants were interviewed once; three were interviewed multiple times to get enough information. Furthermore, a number of participants (7\%) reviewed summary themes and interpretations of the data being collected to validate that researcher's coding/interpretations accurately represented their experiences (member checking). Maximum variation also increased the study's credibility. In order to enhance the reliability of the coding of the participant's statements (confirmability), the interviews and extracted categories were reviewed and verified by two impartial faculty members to confirm agreement on the codes and themes identified. Their perspectives were included. All steps of the study process were described to these two external reviewers and captured for future auditing of the research. Direct quotes, specific examples, and
Table 1 The interview questions of each group of participants
For persons with SCI:

(1) From morning until night, what do you do for yourself?

(2) What adaptive equipment do you use to be able to become physically capable?

(3) What facilities are available to help you?

(4) What does your family do to help you?

(5) What does the healthcare system do to help have a better quality of life?

For family caregivers:

(1) Please explain how you take care of your family member with SCI in a typical day.

(2) What care do you provide?

(3) What aspects of care are difficult for you?

(4) How have you responded to these difficulties?

(5) How can the family help a person with SCI?

For health professionals: (1) Explain the situation for the care of people with spinal cord injury in Iran?

(2) What factors prevent the family empowerment of those with SCI?

(3) What could improve the quality of life and living conditions for these patients?

(4) What are the most important programs and services needed for these patients? 
Table 2 Demographic characteristics of the studied participants

\begin{tabular}{|c|c|c|c|c|c|}
\hline & $\begin{array}{l}\text { Individuals with } \\
\text { SCI Group1 }\end{array}$ & $\begin{array}{l}\text { Family caregivers } \\
\text { Group2 }\end{array}$ & $\begin{array}{l}\text { Health professional } \\
\text { Group3 }\end{array}$ & $\begin{array}{l}\text { Median } \\
\text { (interquartile range) }\end{array}$ & \\
\hline Variables $(N)$ & & & & & total $(N)$ \\
\hline \multirow[t]{3}{*}{ Age range (year) } & $24-63$ & $25-65$ & $35-53$ & $36(31-47) \rightarrow$ Group1 & 19 \\
\hline & & & & $52(42-57) \rightarrow$ Group2 & 13 \\
\hline & & & & $44(38-50) \rightarrow$ Group3 & 11 \\
\hline \multicolumn{6}{|l|}{ Gender } \\
\hline Woman & 5 & 8 & 5 & & \\
\hline Man & 14 & 5 & 6 & & \\
\hline \multicolumn{6}{|l|}{ Education } \\
\hline Primary school & 1 & 5 & 11 & & \\
\hline Secondary school & 11 & 8 & & & \\
\hline College & 7 & & & & \\
\hline \multicolumn{6}{|l|}{ Marital status } \\
\hline Single & 7 & 1 & 1 & & \\
\hline Married & 9 & 11 & 10 & & \\
\hline Divorced & 3 & 1 & 0 & & \\
\hline \multicolumn{6}{|l|}{ Job status } \\
\hline Student & 0 & 1 & 0 & & \\
\hline Worker & 1 & 1 & 0 & & \\
\hline Self-employed & 2 & 2 & 0 & & \\
\hline Employee & 2 & 7 & 11 & & \\
\hline Unemployed & 14 & 2 & 0 & & \\
\hline \multicolumn{6}{|l|}{ Cause of Injury } \\
\hline Car accident & 16 & & & & \\
\hline Falling & 2 & & & & \\
\hline Hit the bullet & 1 & & & & \\
\hline $\begin{array}{l}\text { Range of length of time since SCI } \\
\text { (month) min-max }(12-360)\end{array}$ & & & & $72(24-120)$ & \\
\hline $\begin{array}{l}\text { Type of the caregivers relationship } \\
\text { to the person with SCI Wife }\end{array}$ & & 3 & & & \\
\hline Father & & 2 & & & \\
\hline Mother & & 6 & & & \\
\hline Daughter & & 1 & & & \\
\hline Brother & & 1 & & & \\
\hline \multicolumn{6}{|l|}{ Level of injury } \\
\hline $\mathrm{C} 1-\mathrm{C} 7$ & 5 & & & & \\
\hline $\mathrm{T} 1-\mathrm{T} 2$ & 12 & & & & \\
\hline L1-L5 & 2 & & & & \\
\hline \multicolumn{6}{|c|}{ American SCI Association Impairment Scale } \\
\hline A & 9 & & & & \\
\hline B & 4 & & & & \\
\hline $\mathrm{C}$ & 5 & & & & \\
\hline $\mathrm{D}$ & 1 & & & & \\
\hline
\end{tabular}

precise descriptions gathered from the participants are provided to assist potential generalization (i.e., transferability) to other situations and patients with SCI [18].

\section{Results}

Demographic characteristics of the participants are presented in Table 2. Five main categories emerged from the data analysis: (1) disruption in existential integrity of the individual; (2) constructive life recovery; (3) inhibitors of family-centered empowerment; (4) facilitators of familycentered empowerment and; (5) back on track. Constructive life recovery was selected as the core variable and was a set of strategies participants most frequently used to deal with the injury and its consequences. The categories and subcategories are fully described below:

(There are two appendixes; Appendix 1: Categories/ subcategories and quotes from participants, Appendix 2: Theory diagram: towards constructive life recovery). 


\section{Disruption in existential integrity of the individual}

Participants reported that several dimensions of their lives are affected following SCI. Subcategories that emerged from the analysis are described below:

\section{Potentially harmful emotional reactions}

Negative emotions, such as, denial, anger, and depression are themes included in this subcategory.

\section{Poor social interactions and isolation}

Most of the families and individuals with SCI prefer to stay at home and isolated from others. They cite their reasons as shame over physical impairments, pain and/or muscle spasm, and fear of frustration. Social isolation was somewhat more common than "fear of frustration", which included two themes: "restrictive concerns about employment or an educational situation" and "concerns about the impossibility of marriage".

\section{Family structure transformation}

This subcategory included themes, such as "changes in interpersonal relationships," "changes in the role of family members," and "dealing with family deprivations." Changes in interpersonal relationships included such concepts as harmony of relationships, distressed relationships, and total relationship breakdown. Some of the identified causes of interpersonal relationship disruption were lack of sexual activity with the spouse, blaming a family member for the accident that caused the SCI, and poor financial situations as a result of increased healthcare expenses.

Changes in the role of family members included additional subcategories of "increased workload" followed by "increase in the responsibilities" and "long-term involvement in the role of caregiver." We found that in most cases, one family member assumes the burden of care for the injured person.

Dealing with loss is another problem area for families. This includes loss of work and educational opportunities, loss of comfort, loss of emotional support for spouse and children, financial damage, physical and psychological damage, and loss of dignity in the family.

\section{Difficulties caused by physical problems}

Restricted mobility (e.g., paraplegia and tetraplegia), bowel disorders, sexual disorders, pain and/or muscle spasms, immobilization caused by problems, such as decubitus ulcers, osteoporosis, and heterotopic ossification were frequently mentioned themes.

\section{Constructive life recovery}

This concept was revealed in the data as the core variable and described the strategies most frequently used to deal with participants' greatest concerns about SCI-related impairment, disability, and life management post injury. This core category emerged from three big subcategories, including the following:

\section{Active coping with disability}

This subcategory was comprised of several themes including positive emotions, such as exploration, recovery of hope and motivation, establishing social communications, reaffirming spirituality, correcting faulty thinking, and reforming attitude.

Exploration Most individuals with SCI and their families, especially in the first year post injury, did not have sufficient information about SCI. They obtained knowledge through the Internet, healthcare providers, peers, relatives, workshops presented by SCI associations, and occasionally through TV programming. Health information, governmental and nongovernmental support networks were part of this theme.

Recovery of hope and motivation Within this theme, some participants reported hope and motivation by comparing their own situations to those of other patients and families dealing with more complicated physical impairments (e.g., the loss of a hand or complete quadriplegia), noticing the return of physical sensation and mobility, and a sense of responsibility for the family.

Establishing social relationships Individuals with SCI and their families were trying to reconnect with their social communities, as they may have become isolated post injury. These communications included reestablishing relationships with noninjured peers (i.e., friends and relatives), and building relationships with peers in the patient associations, health centers, research centers, and/or through the Internet (e.g., responding to others with SCI through social media such as Telegram or WhatsApp). Most of those who were in contact with others using social media were young and those with paraplegia.

Reaffirming spirituality This concept emerged from themes, such as trust in God, pilgrimage, prayer, and vows. Most of the individuals with SCI and their families used the term "trust in God" in their interviews. In the Iranian culture, people become closer to God and pray more when they are in trouble. Also, most individuals with SCI consider their disability as the will of God. In the Islamic-Iranian culture, the belief in the "divine test" makes facing challenges easier. 
Participants reported using their faith and spirituality to reduce stress and anxiety, and to cope. The religious practice of the pilgrimage of Imams was another coping strategy.

The other themes in this category were resorting to prayer and vows. Some individuals with SCI and their families vow to do good deeds for the sake of God, if they can overcome current difficulties or improve circumstances. These vows typically include charitable acts, such as giving food or money to those who are in need.

Correcting faulty thinking Cognitive reframing was another theme that emerged from the data. When attitudes and cognitions change, behavior change often follows. Interview data suggested that positive attitudes helped the participants to more effectively cope with daily struggles. This theme included "correcting thinking" and "optimism."

Reforming attitude A number of participants also tried to be more positive about those around them. Interview data suggested that an attitudinal shift makes them less anxious.

\section{Efforts to achieve and promote physical function}

Many persons with SCI, with the support of family caregivers and the rehabilitation team, make efforts to reach physical and functional independence. This subcategory included physical rehabilitation and assistive devices, complementary medicine methods, and achieving self-reliance.

Using physical rehabilitation and assistive devices Strengthening exercises, and the use of assistive devices, such as canes, walkers, AFO's and KFO's, and wheelchairs are included in this category. Rehabilitation services (i.e., occupational therapy and physiotherapy) and home modifications to ensure accessibility also were described. A small number of individuals with SCI with greater financial resources purchased elevators and electric wheelchairs.

Using complementary medicine Some study participants used complementary medicine and expressed an open attitude toward energy therapy (e.g., using physical touch for stress reduction and health), homeopathy, traditional medicine (e.g., treatment based on the body's temperament and individual characteristics, and beliefs related to herbal, animal and mineral medicines), acupuncture, water therapy, and cell therapy.

Achieving self-reliance Most of the participants described significant attempts to become independent. There were two themes: "innovation in building rehabilitation assistance tools by the family" and "efforts for becoming independent in personal affairs." A small number of participants and their families had invented creative devices to assist rehabilitation; some of the participants also tried to do more to take care of their personal affairs. Some families were described as playing an important role in helping the individual with SCI to become more independent.

\section{Efforts for life management}

This subcategory includes concepts of self-awareness, selfcontrol, and life balance.

Thinking and self-awareness Some individuals with SCI and their families have thought about the ramifications of ongoing physical impairment and have become aware that SCI is a lifelong condition that may require alterations in life plans.

Self-control A number of participants explained taking control over themselves and their behavior.

Life balance A number of participants worked to restore a sense of balance to their lives.

\section{Inhibitors of family-centered empowerment}

Several variables that inhibit empowerment of individuals with SCI and their families were identified. The main category of inhibitors of empowerment consists of five sub categories which are described below:

\section{Lack of family and patient education}

One of the most frequently mentioned needs of persons with SCI, their families, and healthcare providers was training and education in the comprehensive management of SCI. Themes included the following:

Lack of proper training programs Participants described a failure to educate patients and families about basic primary health issues associated with SCI.

Independence vs. dependence on others During the interviews, many families expressed the desire to help their injured member as much as possible and seemed unaware of the potential of encouraging greater dependence and furthering unnecessary disability.

\section{Being in problem-oriented healthcare system}

Some participants believed that a portion of the barriers to family-centered empowerment are associated with the healthcare system, itself, and its acute care emphasis. These were identified in themes of: 
Lack of professional competence A number of participants cited negative interactions, lack of communication skills, and lack of SCI knowledge in healthcare providers.

Poor teamwork Teamwork among providers was described as weak.

Lack of patient follow-up system Participants noted a lack of follow-up services or systems to ensure ongoing care.

Lack of government-sponsored home care services Most participants noted the high costs of care without insurance benefits, travel difficulties for rehabilitation therapists, and a lack of SCI awareness in the community.

Lack of shared decision making Most participants and many of the healthcare providers described the need for more shared decisions about SCI care.

\section{Failure to support transition back into the community}

The themes that created this subcategory included the following:

Lack of social facilities The primary codes such as "lack of accessible entertainment places in the community," inaccessible streets and sidewalks," and "inadequate insurance coverage" (which was noted most frequently) created this category.

Lack of financial resources One of the most concerning issues described by the majority of participants was the lack of state funding and the low economic status of many patients.

Some participants said that inadequate financial allocation of resources in our country has significantly affected urban planning, legislation, adaptation, and disability focused services.

Lack of employment opportunities Participants noted the shortage of jobs and a failure to comply with employment laws for disabled people.

\section{Hurtful reactions from others}

Many participants expressed distress with the responses of people in their communities. They described reactions to their physical impairment made them feel socially isolated. Two themes were identified:

Humiliating reactions Many individuals with SCI and some of their families mentioned that the reactions of others felt demeaning and discouraged them from being out in the world.

Pitiful reactions Many participants perceived that others felt sorry for, or stared at them inappropriately.

\section{Secondary impairment}

Some participants described increasing dependence on others, post injury, due to the development of secondary physical impairments. Physical complications, such as carpal tunnel syndrome and pressure ulcers, were specifically identified as playing a role in limiting independence in patients with SCI.

\section{Nonadherence to recommendations for independence}

Nonadherence to recommendations was another subcategory that described barriers to becoming independent in activities of daily living and activities outside the home. The following themes emerged:

Lack of cooperation with family and the healthcare team Family members described the lack of willingness for the injured person to do anything to take care of themselves or work toward independence.

Discounting the experiences of peers with $\mathrm{SCl}$ Some individuals with SCI did not care to learn about or use the experiences of injured peers.

\section{Facilitators of family-centered empowerment}

A number of factors facilitated the family-centered empowerment process. The subcategories described below were identified as enhancing empowerment:

\section{Personal characteristics}

The subcategory of personal characteristics included themes around "religious beliefs," "supportive family," and "disability benefits." Religious beliefs were described as extremely helpful for individuals with SCI and their families. In addition, a family psychological support seemed to facilitate empowerment. Finally, a small number of individuals with SCI received disability income post injury, which partly helped them to pay for costs of care.

\section{High quality rehabilitation services}

The quality of healthcare and the available rehabilitation services were a source of empowerment for patients and their families. 


\section{Benefiting from NGOs and charities}

Participants spoke positively about organizations that provide rehabilitation services at low prices and offer free transportation.

\section{Back on track}

A number of participants reported their lives returned to some sense of normalcy post injury. Some returned to work; some married and had children. This category consisted of two subcategories:

\section{Gradual return to society}

Some individuals with SCI were able to return to their previous jobs or find new jobs with support of their families. Others were able to continue their education.

\section{Recovery of normal life}

Marriage and having children were included in this category.

\section{Discussion}

This qualitative study was an exploration of the process of family-centered empowerment in individuals with traumatic SCI living in Iran. GTM was used to develop our model. The analysis for the present study was based on five main categories, entitled, "disruption in existential integrity of the individual," "constructive life recovery," "inhibitors of family-centered empowerment," "facilitators of familycentered empowerment," and "back on track"

The process of family-centered empowerment in individuals with SCI starts with a disruption in the existential integrity of the injured person. This main category included changes in physical and psychological function, along with alterations in family and social interactions. Egnew stated that the absence of health threatens the existential integrity of the individual as comprehended within a whole related to physical (i.e., body function), mental (i.e., psychological well-being), and social (i.e., interpersonal and family relationship) [19]. The analysis of the interviews conducted with this study population identified content reflective of Egnew's concepts.

Constructive Life Recovery was identified as the core variable in this study. This core variable identified the strategies most frequently used by the participants to cope with the challenges of SCI-related impairment, disability, and overall life management. The findings were that SCI affected the injured person and his/her family, alike. As a result, families and individuals with SCI struggled to cope with issues of a devastating injury and the subsequent physical impairment, while they simultaneously worked toward functional recovery, independence, and successful management of a lifelong condition.

The first subcategory under Constructive Life Recovery was active coping with disability, which included themes of coping with injury, such as exploration, recovery of hope and motivation, reestablishing social relationships, reaffirming spirituality, and a reforming attitude. The existing literature on persons with SCI supports similar findings. Matter et al. reported that people with SCI typically seek information from a variety of resources to learn more about their condition or related issues [20]. Dorsett reported that increasing sensations and movement in paralyzed limbs after a period of time boosted hope in individuals with SCI [21]. Kennedy et al. reported that most individual with SCI eventually reintegrate with their family, friends, and expanded social networks similar to the participants in the current study [22]. Furthermore, reaffirming spirituality in the present findings was similar to Marini et al.'s results. They noted that the majority of persons with SCI used spirituality to cope with their injury and that some patients believed that SCI made them more spiritual, in general [23]. In addition, Kennedy et al. found a correlation between optimism and functional independence in the SCI population [24].

The second subcategory under Constructive Life Recovery included efforts to achieve and promote physical function. Three themes were identified: physical rehabilitation and use of assistive devices, complementary medicine, and achieving self-reliance.

Kehn and Kroll, in a qualitative study, found that individuals with SCI desire to participate in activities, but face a number of obstacles, such as the lack of financial means for rehabilitation equipment [25]. Van Buyten et al. reported that people with SCI used various complementary therapies including massage, acupuncture, and percutaneous electrical therapies to reduce the pain often associated with injury [26]. Lam et al. found that individuals with SCI try to walk with the aid of assistive devices (such as prostheses, orthoses, canes, or walkers) [27]. The theme of achieving self-reliance found in the current analysis included leveraging rehabilitation assistance and working toward independence in personal affairs. Gowan and Roth reported that strong family functioning was related to independence in persons with SCI, which was similarly noted in our findings [28].

Efforts for life management was the third subcategory in the core category of Constructive Life Recovery, which included themes of thinking and self-awareness, self-control, and life balance. Boschen et al. evaluated coping strategies in persons with SCI and indicated that individuals sometimes modified their life goals and altered their expectations toward goals they perceived as more 
achievable. They noted that family members, friends, or rehabilitation professionals could help in this regard, and conversely, that negative attitudes of others could lead to limited choices and a reduced sense of self-control, thus compromising the independence of the individual with SCI [29].

The third main category was entitled, Inhibitors of family-centered empowerment, and addressed barriers to the care and management of persons with SCI. Inhibitors to empowerment were lack of family and patient education, a problem-oriented healthcare system, lack of social facilities, poor financial support, hurtful reactions from others, and unintended dependence. Lack of family and patient education was a broad subcategory including lack of proper patient and family training programs, misconceptions about disability, and lack of family participation and patient in care-related decision-making. Juguera et al. noted that both the patient and family need information, training throughout the process of suffering, and the creation of informal groups of mutual aid [30]. Shields et al. investigated children with physical disabilities and found that barriers for activity included parental behavior, negative attitudes about disability, lack of disability knowledge, and inadequate community facilities [31]. These barriers were similar to those identified by adults with SCI in the present study.

Problem-oriented healthcare systems that focus on acute problems at the expense of chronic care management were seen as inhibitors to empowerment. Some of the issues identified were lack of comprehensive services, lack of professional expertize, poor healthcare teamwork, lack of a patient follow-up system, and lack of governmentsponsored home care services. The lack of professional competence and expertize was similar to the concerns raised by Chang who was working to develop a successful rehabilitation model. Chang described the importance of specialized training for the members of the rehabilitation team, which included not only technical skills, but also communication competencies to provide appropriate care to the SCI population [32]. Furthermore, home care in Iran is not government supported. Nikbakht-Nasrabadi and ShabanyHamedan have called for the establishment of a home healthcare system for helping this population [33].

Lack of social facilities, low socio-economic status, hurtful reactions from others, unintended dependence, and nonadherence to recommendations for independence were subcategories and viewed as barriers to family-centered empowerment. Physical and financial dependence on one or more family members is an obstacle; moreover, inadequate social facilities, restricted access to healthcare services, and limited social support networks can impair the empowerment of people with physical impairment and disability [34]. Hurtful reactions from others was a subcategory of the inhibitors. Hosseinigolafshani et al. found that individuals with SCI believed people that do not have any experience with or exposure to SCI, and often expressed hurtful, negative, and misinformed attitudes toward injured persons. These reactions were described by persons with SCI as extremely painful, undermining, and in some cases were described as being more difficult to cope with than the actual SCI event. Importantly, the negative attitudes of others were reported to worsen the injured persons' sense of hope and confidence [35]. Nonadherence to recommendations for independence was another subcategory of barriers to empowerment. This subcategory captured persons with SCI who were unwilling to engage in their care and develop independence in functioning. It seemed that some participants struggled to come to terms with the fact that they have sustained a life changing injury that requires them to modify almost everything in their lives. Olney et al. found that one of the consequences of such denial is poor psychosocial adjustment, which makes the follow-up and treatment of patients difficult [36].

The fourth main category of family-centered empowerment was called facilitators of family-centered empowerment. Personal characteristics and benefiting from quality services were subcategories. Personal characteristics included religious beliefs, a supportive family, and a professional position before injury. Löfvenmark et al. conducted a qualitative study on individuals with SCI and reported findings, which emphasized strong family support, adequate source of income, and faith as strong empowerment facilitators [37]. High quality rehabilitation services were another subcategory in the fourth main category. According to a World Health Organization report, deficient rehabilitation care for people with physical impairments and disabilities is an obstacle to full societal integration and that this is a problem not just in acute care, but across one's lifespan. Therefore, quality services may be a facilitator in the family empowerment path [38]. Benefiting from NGOs and charities was another subcategory. Khan et al. stated that NGOs and charities have been essential in funding rehabilitation services to help empower affected people [39].

Back on track was the final main category in the present study. It had two subcategories including gradual return to society and recovery of normal life. Lidal et al. found that return to work rates following SCI ranged from 11.5 to $74 \%$ [40]. In a qualitative study conducted by Pashaei Sabet et al., findings included that people with disability seek return to normal conditions and gradually adapt to their problems over time [41]. The themes of marriage and having children were included in the subcategory of return to normal life. Zahra Khazaeipour et al.'s study noted that childbearing after SCI makes individuals feel that they have returned to the life they expected prior to injury [42] and this finding was similar to the sentiments expressed in the present study. 


\section{Limitations}

One of the limitations of the current study was the variability in the study population of level of SCI. Because different types of SCI might be associated with different challenges and experiences, some of the findings might not be generalizable to a larger SCI population. Furthermore, the cause of injury was a result of trauma for all of the participants and their families. As a result, the findings in this study population might not generalize to the broader population of persons with SCI. Finally, there are geographic constraints. Because participants were recruited from care centers in Tehran province, results might not be generalizable to other countries.

\section{Conclusion}

Our investigation of family-centered empowerment in individuals with traumatic SCI found the process to be dynamic, complex, multifaceted, and ongoing. We generated a conceptual model of these processes through the methodical gathering and analysis of interview data from individuals with SCI, their family caregivers, and their healthcare providers. Numerous changes across several dimensions in the lives of patients with SCI and their families were identified, including the significant challenges of coping with impairment and disability, while simultaneously working toward functional independence and management of life following injury. Factors inhibiting empowerment were categorized as deficiencies in patient education and specialized rehabilitation services, acute focused healthcare, and negative reactions from others about SCI-associated impairment. Factors determined to facilitate empowerment were categorized as psycho-social-vocational characteristics of the patient, high quality rehabilitation care, and support through NGOs and charities. According to the barriers mentioned, further research is needed to provide a prescriptive model that can improve the overall health and independence of the SCI population.

\section{Clinical messages}

Education and communication need to be improved in healthcare systems and in providers' work practices to achieve integrated rehabilitation and family-centered empowerment for persons with SCI.

Self-care education is needed for individuals with SCI and their families.

SCI awareness is necessary in Iranian society for both individuals with SCI as well as the larger population.

\section{Data availability}

The datasets generated and/or analyzed during the current study are not publicly available due to confidentiality and privacy of the participants but are available from the corresponding author on reasonable request.

Funding This research received no specific grant from any funding agency in the public, commercial, or not-for-profit sectors.

Author contributions MS responsible for suggesting topic, performing and typing interviews, analyzing and interpreting the interviews, writing the paper. ANN was responsible for interpreting the interviews, helping to acquiring data, drafting and revising the article. NM analyzing the interviews, drafting, and revising the article. SP helping to translation, critical revise and drafting the article. ANN and NM assessed the accuracy of analysis and extracted themes, and their perspectives were applied.

\section{Compliance with ethical standards}

Conflict of interest The authors declare that they have no conflict of interest.

Ethics section We certify that all applicable institutional and governmental regulations concerning the ethical use of human volunteers were followed during the course of this research.

Publisher's note: Springer Nature remains neutral with regard to jurisdictional claims in published maps and institutional affiliations.

\section{References}

1. Fitzharris M, Cripps R, Lee B. Estimating the global incidence of traumatic spinal cord injury. Spinal Cord. 2014;52:117.

2. Hagen E, Faerestrand S, Hoff J, Rekand T, Gronning M. Cardiovascular and urological dysfunction in spinal cord injury. Acta Neurol Scand. 2011;124:71-78.

3. Abrams GM, Ganguly K. Management of chronic spinal cord dysfunction. Contin: Lifelong Learn Neurol. 2015;21:188-200. https://doi.org/10.1212/01.CON.0000461092.86865.a4.

4. WHO. Spinal cord injury. Geneva: WHO; 2013. http://www.who. int/mediacentre/factsheets/fs384/en/. Accessed 2 Oct 2014. In.

5. Rahimi-Movaghar V, Saadat S, Rasouli MR, Ganji S, Ghahramani M, Zarei M-R, et al. Prevalence of spinal cord injury in Tehran, Iran. J Spinal Cord Med. 2009;32:428-31.

6. Krueger H, Noonan VK, Trenaman LM, Joshi P, Rivers CS. The economic burden of traumatic spinal cord injury in Canada. Chronic Dis Inj Can. 2013;33:113-22.

7. French DD, Campbell RR, Sabharwal S, Nelson AL, Palacios PA, Gavin-Dreschnack D. Health care costs for patients with chronic spinal cord injury in the Veterans Health Administration. J Spinal Cord Med. 2007;30:477-81PMC2141733.

8. Tulsky DS, Kisala PA, Victorson D, Tate D, Heinemann AW, Amtmann D, et al. Developing a contemporary patient-reported outcomes measure for spinal cord injury. Arch Phys Med Rehabil. 2011;92(10, Supplement):S44-S51. https://doi.org/10.1016/j.apmr. 2011.04.024

9. Rosland A-M, Heisler M, Choi H-J, Silveira MJ, Piette JD. Family influences on self-management among functionally independent adults with diabetes or heart failure: do family members hinder as much as they help? Chronic Illn. 2010;6:22-33. 
10. Gajraj-Singh P. Psychological impact and the burden of caregiving for persons with spinal cord injury (SCI) living in the community in Fiji. Spinal Cord. 2011;49:928 https://doi.org/10.1038/ sc.2011.15.

11. Reinhard SC, Levine C, Samis S. Home alone: family caregivers providing complex chronic care. Washington, DC: AARP Public Policy Institute; 2012.

12. Adinolfi P, Starace F, Palumbo R. Health outcomes and patient empowerment: The case of health budgets in Italy. J Health Manag. 2016;18:117-33.

13. Salahi S, Javanbakhtian R, Hasheminia SA, Habibzadeh H. The effect of family-centered empowerment model on quality of life of hemodialysis patients. J Urmia Nurs Midwifery Facul 2012;10:1-7.

14. Mbae FN, Mukulu E, Kihoro JM. Critical literature review on how individual socio-economic empowerment occurs in youth groups. Int J Acad Res Account, Financ Manag Sci. 2016;6:119-30.

15. Martin PY, Turner BA. Grounded theory and organizational research. J Appl Behav Sci. 1986;22:141-57.

16. Rohatinsky N, Goodridge D, Rogers MR, Nickel D, Linassi G. Shifting the balance: conceptualising empowerment in individuals with spinal cord injury. Health Soc Care Community. 2017;25:769-79.

17. McCann TV, Clark E. Grounded theory in nursing research: Part 1-Methodology. Nurse Res. 2003;11:7.

18. Rolfe G. Validity, trustworthiness and rigour: quality and the idea of qualitative research. J Adv Nurs. 2006;53:304-10.

19. Egnew TR. The meaning of healing: transcending suffering. Ann Fam Med. 2005;3:255-62.

20. Matter B, Feinberg M, Schomer K, Harniss M, Brown P, Johnson K. Information needs of people with spinal cord injuries. J Spinal Cord Med. 2009;32:545-54.

21. Dorsett $P$. The importance of hope in coping with severe acquired disability. Aust Soc Work. 2010;63:83-102.

22. Kennedy P, Lude P, Taylor N. Quality of life, social participation, appraisals and coping post spinal cord injury: a review of four community samples. Spinal Cord. 2006;44:95.

23. Marini I, Glover-Graf NM. Religiosity and spirituality among persons with spinal cord injury: attitudes, beliefs, and practices. Rehabil Couns Bull. 2011;54:82-92.

24. Kennedy P, Evans M, Sandhu N. Psychological adjustment to spinal cord injury: the contribution of coping, hope and cognitive appraisals. Psychol Health Med. 2009;14:17-33.

25. Kehn M, Kroll T. Staying physically active after spinal cord injury: a qualitative exploration of barriers and facilitators to exercise participation. BMC Public Health. 2009;9:168 https://doi. org/10.1186/1471-2458-9-168.Pmc2694784.

26. Van Buyten JP, Van Zundert J, Vueghs P, Vanduffel L. Efficacy of spinal cord stimulation: 10 years of experience in a pain centre in Belgium. Eur J Pain. 2001;5:299-307. https://doi.org/10.1053/ eujp.2001.0249.

27. Lam T. A systematic review of functional ambulation outcome measures in spinal cord injury. Spinal Cord. 2008;46:246-54. https://doi.org/10.1038/sj.sc.3102134.Pmc3095631.
28. McGowan MB, Roth S. Family functioning and functional independence in spinal cord injury adjustment. Paraplegia. 1987;25:357-65. https://doi.org/10.1038/sc.1987.64.

29. Boschen KA, Tonack M, Gargaro J. Long-term adjustment and community reintegration following spinal cord injury. Int $\mathrm{J}$ Rehabil Res. 2003;26:157-64.

30. Juguera Rodriguez L, Pardo Rios M, Leal Costa C. Relatives of people with spinal cord injury: a qualitative study of caregivers' metamorphosis. Spinal Cord. 2018;56:548-59. https://doi.org/10. 1038/s41393-018-0092-0

31. Shields N, Synnot AJ, Barr M. Perceived barriers and facilitators to physical activity for children with disability: a systematic review. Br J Sports Med. 2012;46:989-97.

32. Chung B-Y, Xu Y. Developing a rehabilitation model of breast cancer patients through literature review and hospital rehabilitation programs. Asian Nurs Res. 2008;2: 55-67.

33. Nikbakht-Nasrabadi A, Shabany-Hamedan M. Providing healthcare services at home-a necessity in Iran: a narrative review article. Iran J Public Health. 2016;45:867-74.

34. Rimmer JH, Rowland JL. Health promotion for people with disabilities: implications for empowering the person and promoting disability-friendly environments. Am J Lifestyle Med. 2008;2:409-20.

35. Hosseinigolafshani Z, Abedi H, Ahmadi F. What are the people's attitudes toward spinal cord injury victims (from common to elite). Iran J Nurs Midwifery Res. 2014;19:266-72.

36. Olney MF, Brockelman KF, Kennedy J, Newsom MA Do you have a disability? A population-based test of acceptance, denial, and adjustments among adults with disabilities in the US. J Rehabil 2004;70:4-9.

37. Löfvenmark I, Norrbrink C, Nilsson Wikmar L, Löfgren M. 'The moment I leave my home-there will be massive challenges': experiences of living with a spinal cord injury in Botswana. Disabil Rehabil. 2016;38:1483-92.

38. WHO. World report on disability. Geneva: WHO; 2011. http://www.who.int/medicines/news/2018/presentation_SanaHa feez-WHO-Champion-assistive-products/en/.

39. Khan F, Amatya B, Mannan H, Rathore F. Neurorehabilitation in developing countries: challenges and the way forward. Phys Med Rehabil Int. 2015;2:1070.

40. Lidal IB, Huynh TK, Biering-Sørensen F. Return to work following spinal cord injury: a review. Disabil Rehabil. 2007; 29:1341-75.

41. Pashaei Sabet F, Norouzi Tabrizi K, Khankeh HR, Saadat S, Ali Abedi H, Bastami A. Experience with Limb Trauma: A Thematic Analysis. Trauma Mon. 2017;22:e64928 https://doi.org/10.5812/ traumamon.38208.

42. Khazaeipour Z, Nikbakht-Nasrabadi A, Mohammadi N, Salehi-Nejad A, Shabany M The childbearing experience of women with spinal cord injury in Iran: a phenomenological study. Spinal Cord 2018. https://doi.org/10.1038/s41393-0180162-3. 